\title{
Article
}

\section{The Effect of Night Duty of Pharmacists on Sleepiness and Concentration at Daytime}

\author{
Claus Werner Biechele ${ }^{1, *(\mathbb{D}}$, Martin Glos $^{1} \mathbb{D}$, Ingo Fietze ${ }^{1,2}$, Jürgen Kurths ${ }^{1,3}$ and Thomas Penzel ${ }^{1,4}(\mathbb{D})$ \\ 1 Interdisciplinary Sleep Medicine Center, Charité Universitätsmedizin Berlin, 10117 Berlin, Germany; \\ martin.glos@charite.de (M.G.); ingo.fietze@charite.de (I.F.); kurths@pik-potsdam.de (J.K.); \\ thomas.penzel@charite.de (T.P.) \\ 2 Department of Medicine, The Fourth People' Hospital of Guangyuan City, Guangyuan 628000, China \\ 3 Physics Department, Humboldt University, 12489 Berlin, Germany \\ 4 Department of Human and Animal Physiology, Saratov State University, 410012 Saratov, Russia \\ * Correspondence: claus-werner.biechele@charite.de
}

Citation: Biechele, C.W.; Glos, M.; Fietze, I.; Kurths, J.; Penzel, T. The Effect of Night Duty of Pharmacist on Sleepiness and Concentration at Daytime. Int. J. Environ. Res. Public Health 2021, 18, 9211. https:// doi.org/10.3390/ijerph18179211

Academic Editor: Paul B. Tchounwou

Received: 20 July 2021

Accepted: 29 August 2021

Published: 31 August 2021

Publisher's Note: MDPI stays neutral with regard to jurisdictional claims in published maps and institutional affiliations.

Copyright: (c) 2021 by the authors. Licensee MDPI, Basel, Switzerland. This article is an open access article distributed under the terms and conditions of the Creative Commons Attribution (CC BY) license (https:/ / creativecommons.org/licenses/by/ $4.0 /)$.

\begin{abstract}
Background: The changing responsibilities of pharmacists contribute to a lack of qualified pharmacists to fill vacant positions, particularly in rural areas. Consequently, pharmacy managers cover various duties, including an increasing number of nights being on duty that can impair daytime concentration and performance. The objective of the study was to assess the effect of night duties on daytime sleepiness, sleep quality, and concentration abilities of pharmacists. Methods: 22 pharmacists, both sexes, aged 27 to 60 years, were recruited and their sleep time, sleep efficiency, and mobility (actigraphy) were assessed during a night on duty and a control night using an actimetry. Daytime sleepiness and concentration were assessed using standardized questionnaires (ESS, KSS, d2-R). Results: Significant differences were observed between the night shift and control nights with respect to sleep time, sleep efficiency, and mobility. Daytime sleepiness was significantly increased after night shifts (ESS: 11.64 vs. 2.09; KSS: 6.77 vs. 2.41 after a night shift and control night, respectively; $p<0.001$ ) and concentration diminished compared to control nights (d2-R KL: 220.95 vs. 260.36 after a night shift and control night, respectively; $p<0.001$ ). Conclusions: The results provide evidence that night duties lead to high daytime sleepiness in pharmacists, which in turn may negatively affect their ability to concentrate and their error rate. Existing regulations on emergency pharmacy services should be reconsidered regarding the safety of the pharmaceutical supply.
\end{abstract}

Keywords: pharmacists; night shift; concentration; actigraphy; sleepiness

\section{Introduction}

The shortage of pharmacies and pharmacists in Germany is reflected by a continuous decline in the number of community pharmacies during the past 20 years. Central reasons for this phenomenon are the increase in online orders of medicines and staffing difficulties due to a shift in the roles of pharmacists and unfilled positions [1]. Structurally weak rural regions are particularly affected. Likewise, the demographic change of the population with an ongoing shift of the age pyramid causes many pharmacy managers to retire, and often no replacement is found. A general trend towards part-time work and a lacking willingness to become self-employed intensify the problem. The shift of commercially relevant aspects of the medicine trade to the internet also means that pharmacists are increasingly involved in activities such as blistering, medication analysis, and laboratory work [2]. Administrative activities such as record keeping and quality management have also increased.

Pharmacy managers must therefore cover an increasing number of tasks, including more night shifts and emergency services, which means that they must work both at night and on the following day, with an overall increased number of night shifts. Usually, a night shift lasts $12 \mathrm{~h}$ and a day shift lasts $8-12 \mathrm{~h}$. Therefore, a pharmacist on night and day 
duty may potentially work for $24 \mathrm{~h}$ in a row. Considering the responsibility of pharmacists in the preparation of prescriptions, medication analysis, verification of blistering, and care of senior citizens' homes, this raises a relevant issue regarding the safety of medicine supply, which could be jeopardized by extended working hours of pharmacists [3]. In particular, mistakes could be made by confusing similar sounding or looking medications, miscalculating the correct dosage, or misinterpreting relevant information.

In this context, circadian periodicity is of particular importance. Physical activity and sleep behavior are linked to the synchronization of the circadian rhythm. Sleeping and waking are considered active endogenous rhythms regulated in the central nervous system. The circadian phase is of central importance for mental regeneration but also has a substantial influence on immunity, memory, and metabolism [4-8]. If the circadian periodicity is disturbed, for example, by night or shift work, there is a shift in sleep and wake phases and thus also a shift in physical and cognitive activity.

Significant for the evaluation of sleep deprivation in different occupational groups are the observed intra- and inter-individual differences [9]. Studies in healthcare-related occupations have demonstrated that interrupted sleep phases impact daytime sleepiness $[6,10]$, and that concentration is impaired by lack of sleep [11,12]. James et al. noted impaired cognitive effectiveness of nurses following a $12 \mathrm{~h}$ night shift [11], and Thun et al. [6] detected impairments of everyday memory in nurses working night shifts. Costa et al. observed mood changes in medical residents after working all night [12], while Sanchez et al. [13] noted reduced attention and concentration ability as well as delays in the response to stimuli.

Therefore, the present study aimed to determine the impact of night work on the daytime sleepiness and concentration ability of pharmacists to identify aspects that should be considered for a change in pharmacy policy.

\section{Materials and Methods}

\subsection{Study Design}

Practicing pharmacists with night shifts were recruited into the study. As this was a pilot study, no particular inclusion or exclusion criteria were defined other than participation in night shift duties at a community pharmacy, an age lower than 60 years, and a Pittsburgh Sleep Quality Index (PSQI) value of $\leq 5$, indicating good sleep quality for the past four weeks [14]. The study was conducted by distributing three standardized questionnaires, quantifying sleepiness and concentration ability, and an actimeter, recording rest and mobility during the night. The study procedure was the same for all participants: The control night was assessed first, followed by the night shift.

\subsection{Actimetry}

Actimetry was performed using the MotionWatch 8 (CamNtech Ltd., Cambridge, UK) worn by the pharmacists on the non-dominant wrist during one night shift and during one control night to allow for a comparison. The actimeter used was the, version 1.2.26a. Data was recorded between 10 p.m. and 8 a.m. and analyzed using MotionWatch8's software MotionWare (ver. 1.2.26a, CamNtech Ltd., Cambridge, UK). The following parameters from the actimetry were evaluated: activity, mobility during the night, sleep time, sleep quality, sleep duration. Participants were asked to document the time of switching off the light and each time they got up.

\subsection{Daytime Sleepiness and Concentration Ability}

Daytime sleepiness was assessed after each night with the Karolinska Sleepiness Scale (KSS, 9-point sleepiness scale from $1=$ "extremely alert" to $9=$ "very sleepy") and the Epworth Sleepiness Scale (ESS, sleepiness scale with 8 items of maximum 3 points each, 24 = maximum total score) questionnaires, while the $\mathrm{d} 2-\mathrm{R}$ test was employed to assess the concentration ability. KSS is a scale of situational sleepiness and measures the subjective level of sleepiness at a particular time during the day. The subject indicates which level on the scale best reflects the state during the last $10 \mathrm{~min}$. The test assesses 
daytime sleepiness for a defined period of the previous weeks. If the test subject scores 10 or higher, a sleep medicine evaluation may be indicated. The $\mathrm{d} 2-\mathrm{R}$ test is used to measure concentration in tasks that require attention (focused attention). It measures the subject's ability to concentrate and the speed and accuracy with which similar visual stimuli can be distinguished (detail discrimination).

\subsection{Statistical Analysis}

Descriptive statistics (mean, standard deviation, median, minimum, maximum) were calculated to determine sleep duration, sleep efficiency, mobility, and the questionnaire and $\mathrm{d} 2 \mathrm{R}$ results. Means of all participants were compared with a paired t-test between the control night and the night shift. Cohen's d was calculated to assess the practical implications of observed differences. Correlation analyses were conducted to identify factors relevant for daytime sleepiness and concentration.

\section{Results}

\subsection{Participant Characteristics}

The characteristics of the study cohort $(n=22)$ are listed in Table 1 . The participants had an average age of 46.5 years ( \pm 9.62 years, range: $27-60$ years) and an average PSQI of $2.18( \pm 0.96$, range: $0-4)$. Seven participants $(31.8 \%)$ were male. $63.6 \%$ of the participants $(n=14)$ reported no previous diseases, while one participant each $(4.5 \%)$ reported previous high blood pressure, Colitis ulcerosa, mildly elevated blood pressure, neurodermitis, irritable stomach, rheumatism, dry eye, or arthritis. Eight participants did not take any medications, while one participant each (4.5\%) took cortisone cream, bisoprolol, and HCT, acupuncture, or globuli. Nutritional supplements (protein shakes, glucosamine, chondroitin, magnesium, vitamin B12, salofalk, B-vitamins, zinc, selenium) were taken by one participant each $(4.5 \%)$. Three of the 22 recruited participants were excluded from further assessments because Actiwatch data were not recorded for at least one night.

Table 1. Participant characteristics $(n=22)$. PSQI, Pittsburgh Sleep Quality Index; SD, standard deviation; BMI, Body Mass Index. PSQI, body weight, height, and BMI were measured before the control night, the age was determined before the night shift.

\begin{tabular}{cccccc}
\hline Variable & Mean & SD & Median & Minimum & Maximum \\
\hline PSQI & 2.18 & 0.96 & 2 & 0 & 4 \\
Age & 46.45 & 9.62 & 45.50 & 27 & 60 \\
Body weight $(\mathrm{kg})$ & 72 & 16.05 & 68.50 & 52 & 102 \\
Height $(\mathrm{m})$ & 1.72 & 0.09 & 1.70 & 1.59 & 1.91 \\
BMI $\left(\mathrm{kg} / \mathrm{m}^{2}\right)$ & 24.24 & 4.29 & 23.47 & 18.91 & 37.18 \\
\hline
\end{tabular}

\subsection{Sleep Time and Sleep Efficiency}

On average, $1.82( \pm 1.76)$ prescription medicines and $5.5( \pm 2.89)$ pharmacy-only medicines were administered and $5( \pm 3.32)$ calls were answered during the night shift between 10 p.m. and 8 a.m. The sleep time and sleep efficiency were assessed within three time frames: 10 p.m. to 8 a.m., 11 p.m. to 7 a.m., and 12 a.m. to 6 a.m. The results are listed in Table 2 in comparison to the control night and the night shift. The data between the participants varied only slightly, which indicates similar sleep times and efficiencies. The difference between the night shift and the control night decreased more the smaller the time window was. For example, between 10 p.m. and 8 a.m., the participants slept on average about 72 min less on night duty than in the control night. In the 24 to 6 a.m. period, this difference decreased to an average of about $20 \mathrm{~min}$. The same pattern was observed with sleep efficiency, where the difference between night duty and control night also decreased as the time window was decreased. Interestingly, the sleep efficiency increased overall as the time window decreased, both during the night shift and in the control night. Table 3 lists the statistical evaluation of differences in the sleep quality and efficiency between the control night and the night shift. The mean sleep time during the night shift was 
significantly less than the sleep time during the control night for the time windows of 10 p.m. to 8 a.m. $(p<0.001)$ and 11 p.m. and 7 a.m. $(p<0.01)$. The differences between the shortest time window of 12 a.m. to 6 a.m. did not significantly differ $(p=0.071)$. Sleep efficiency significantly differed between the night shift and the control night for all time windows (Table 3). Cohen's d was calculated to determine the practical significance of these statistically significant differences calculated with the t-test. For the time window of 10 p.m. to 8 a.m., Cohen's $d$ for the sleep time was -1.30 , for the time window 11 p.m. to 7 a.m. -1.09 , and for the smallest time window of 12 a.m. to 6 a.m. it was -0.61 . Therefore, Cohen's d surpassed the critical value of 0.57 for all three time periods assessed [15] (Table 3). The same was found for differences in sleep efficiency.

Table 2. Sleep time, sleep efficiency, mobile/immobile minutes, during the control night and the night shift $(\mathrm{n}$ total $=38$, $\mathrm{n}$ night shift $=19$, $\mathrm{n}$ control night $=19)$. SD, standard deviation.

\begin{tabular}{|c|c|c|c|c|c|c|c|}
\hline Variable & Time & Type of Night & Mean & SD & Median & Minimum & Maximum \\
\hline \multirow{9}{*}{ Sleep time } & \multirow{3}{*}{10 p.m. to 8 a.m. } & Total & 323.53 & 65.70 & 316.50 & 168 & 468 \\
\hline & & Night shift & 287.32 & 48.55 & 287 & 168 & 361 \\
\hline & & Control night & 359.74 & 61.21 & 361 & 257 & 468 \\
\hline & \multirow{3}{*}{11 p.m. to 7 a.m. } & Total & 270.37 & 50.44 & 265 & 146 & 375 \\
\hline & & Night shift & 246 & 43.07 & 253 & 146 & 301 \\
\hline & & Control night & 294.74 & 46.06 & 284 & 217 & 375 \\
\hline & \multirow{3}{*}{12 a.m. to 6 a.m. } & Total & 211.50 & 35.01 & 207.50 & 120 & 282 \\
\hline & & Night shift & 201.16 & 32.41 & 203 & 120 & 252 \\
\hline & & Control night & 221.84 & 35.27 & 215 & 173 & 282 \\
\hline \multirow{9}{*}{ Sleep efficiency } & \multirow{3}{*}{10 p.m. to 8 a.m. } & Total & 67.41 & 13.68 & 65.95 & 35 & 97.50 \\
\hline & & Night shift & 59.86 & 10.11 & 59.80 & 35 & 75.20 \\
\hline & & Control night & 74.95 & 12.74 & 75.20 & 53.50 & 97.50 \\
\hline & \multirow{3}{*}{11 p.m. to 7 a.m. } & Total & 70.40 & 13.14 & 69.10 & 38 & 97.70 \\
\hline & & Night shift & 64.05 & 11.21 & 65.90 & 38 & 78.40 \\
\hline & & Control night & 76.76 & 12 & 74 & 56.50 & 97.70 \\
\hline & \multirow{3}{*}{12 a.m. to 6 a.m. } & Total & 73.78 & 11.96 & 72.70 & 41.80 & 97.90 \\
\hline & & Night shift & 69.88 & 11.28 & 70.50 & 41.80 & 87.50 \\
\hline & & Control night & 77.68 & 11.62 & 74.70 & 62.50 & 97.90 \\
\hline \multirow{9}{*}{ Immobile minutes } & \multirow{3}{*}{10 p.m. to 8 a.m. } & Total & 357.16 & 61.92 & 353 & 201 & 476 \\
\hline & & Night shift & 322.58 & 50.05 & 328 & 201 & 405 \\
\hline & & Control night & 391.74 & 53.39 & 395 & 291 & 476 \\
\hline & \multirow{3}{*}{11 p.m. to 7 a.m. } & Total & 297.82 & 47.33 & 306 & 173 & 381 \\
\hline & & Night shift & 273.63 & 45.14 & 285 & 173 & 338 \\
\hline & & Control night & 322 & 36.51 & 322 & 247 & 381 \\
\hline & \multirow{3}{*}{12 a.m. to 6 a.m. } & Total & 232.50 & 31.30 & 235 & 143 & 286 \\
\hline & & Night shift & 223.05 & 32.66 & 231 & 143 & 267 \\
\hline & & Control night & 241.95 & 27.55 & 240 & 193 & 286 \\
\hline \multirow{9}{*}{ Mobile minutes } & \multirow{3}{*}{10 p.m. to 8 a.m. } & Total & 73.92 & 38.51 & 73 & 4 & 176 \\
\hline & & Night shift & 84 & 36.28 & 73 & 43 & 176 \\
\hline & & Control night & 63.84 & 38.95 & 71 & 4 & 155 \\
\hline & \multirow{3}{*}{11 p.m. to 7 a.m. } & Total & 55.97 & 25.81 & 58 & 3 & 107 \\
\hline & & Night shift & 61.63 & 22.92 & 57 & 23 & 107 \\
\hline & & Control night & 50.32 & 27.87 & 59 & 3 & 102 \\
\hline & \multirow{3}{*}{12 a.m. to 6 a.m. } & Total & 42.55 & 20.45 & 43 & 2 & 95 \\
\hline & & Night shift & 48.11 & 16.17 & 52 & 19 & 81 \\
\hline & & Control night & 37 & 23.08 & 36 & 2 & 95 \\
\hline
\end{tabular}


Table 3. Comparison of sleep time, sleep efficiency, and mobile/immobile minutes between the control night and the night shift. CI, confidence interval; SD, standard deviation.

\begin{tabular}{|c|c|c|c|c|c|c|c|c|}
\hline \multirow{2}{*}{ Variable } & \multirow{2}{*}{ Time } & \multicolumn{3}{|c|}{ Mean (SD) } & \multirow{2}{*}{$t$} & \multirow{2}{*}{$p$} & \multirow{2}{*}{$95 \% \mathrm{CI}$} & \multirow{2}{*}{ Cohen's d } \\
\hline & & Night Shift & Control Night & Difference & & & & \\
\hline \multirow{3}{*}{ Sleep time } & 10 p.m. to 8 a.m. & $\begin{array}{l}287.32 \\
(48.55)\end{array}$ & $\begin{array}{l}359.74 \\
(61.22)\end{array}$ & $\begin{array}{l}-72.42 \\
(61.86)\end{array}$ & -5.10 & $<0.001$ & $\begin{array}{c}{[-102.24} \\
-42.61]\end{array}$ & -1.30 \\
\hline & 11 p.m. to 7 a.m. & $\begin{array}{c}246 \\
(43.07)\end{array}$ & $\begin{array}{l}294.74 \\
(46.06)\end{array}$ & $\begin{array}{l}-48.74 \\
(58.68)\end{array}$ & -3.62 & 0.002 & $\begin{array}{c}{[-77.01} \\
-20.46]\end{array}$ & -1.09 \\
\hline & 12 a.m. to 6 a.m. & $\begin{array}{l}201.16 \\
(32.41)\end{array}$ & $\begin{array}{l}221.84 \\
(35.27)\end{array}$ & $\begin{array}{l}-20.68 \\
(46.97)\end{array}$ & -1.92 & 0.071 & $\begin{array}{c}{[-43.32 ;} \\
1.95]\end{array}$ & -0.61 \\
\hline \multirow{3}{*}{$\begin{array}{c}\text { Sleep } \\
\text { efficiency }\end{array}$} & 10 p.m. to 8 a.m. & $\begin{array}{c}59.86 \\
(10.11)\end{array}$ & $\begin{array}{c}74.95 \\
(12.74)\end{array}$ & $\begin{array}{l}-15.08 \\
(12.88)\end{array}$ & -5.10 & $<0.001$ & $\begin{array}{c}{[-21.29} \\
-8.87]\end{array}$ & -1.30 \\
\hline & 11 p.m. to 7 a.m. & $\begin{array}{c}64.05 \\
(11.21)\end{array}$ & $\begin{array}{c}76.76 \\
(12)\end{array}$ & $\begin{array}{l}-12.71 \\
(15.26)\end{array}$ & -3.63 & 0.002 & $\begin{array}{c}{[-20.06 ;} \\
-5.36]\end{array}$ & -1.09 \\
\hline & 12 a.m. to 6 a.m. & $\begin{array}{c}69.88 \\
(11.28) \\
\end{array}$ & $\begin{array}{c}77.68 \\
(11.62) \\
\end{array}$ & $\begin{array}{c}-7.8 \\
(16.04) \\
\end{array}$ & -2.12 & 0.048 & $\begin{array}{c}\text { [-15.53; } \\
-0.07]\end{array}$ & -0.68 \\
\hline \multirow{3}{*}{$\begin{array}{l}\text { Immobile } \\
\text { minutes }\end{array}$} & 10 p.m. to 8 a.m. & $\begin{array}{l}322.58 \\
(50.05)\end{array}$ & $\begin{array}{l}391.74 \\
(53.39)\end{array}$ & $\begin{array}{l}-69.16 \\
(47.30)\end{array}$ & -6.37 & $<0.001$ & $\begin{array}{l}\text { [-91.95; } \\
-46.36]\end{array}$ & -1.33 \\
\hline & 11 p.m. to 7 a.m. & $\begin{array}{l}273.63 \\
(45.14)\end{array}$ & $\begin{array}{c}322 \\
(36.51)\end{array}$ & $\begin{array}{l}-48.37 \\
(48.23)\end{array}$ & -4.37 & $<0.001$ & $\begin{array}{l}{[-71.62 ;} \\
-25.12]\end{array}$ & -1.17 \\
\hline & 12 a.m. to 6 a.m. & $\begin{array}{l}223.05 \\
(32.66) \\
\end{array}$ & $\begin{array}{l}241.95 \\
(27.55) \\
\end{array}$ & $\begin{array}{l}-18.89 \\
(38.30) \\
\end{array}$ & -2.15 & 0.045 & $\begin{array}{c}{[-37.36} \\
-0.43]\end{array}$ & -0.62 \\
\hline \multirow{3}{*}{$\begin{array}{l}\text { Mobile } \\
\text { minutes }\end{array}$} & 10 p.m. to 8 a.m. & $\begin{array}{c}84 \\
(36.28)\end{array}$ & $\begin{array}{c}63.84 \\
(38.95)\end{array}$ & $\begin{array}{c}20.16 \\
(55.69)\end{array}$ & 1.58 & 0.132 & {$[-6.68 ; 47]$} & 0.54 \\
\hline & 11 p.m. to 7 a.m. & $\begin{array}{c}61.63 \\
(22.92)\end{array}$ & $\begin{array}{c}50.32 \\
(27.87)\end{array}$ & $\begin{array}{c}11.32 \\
(32.45)\end{array}$ & 1.52 & 0.146 & $\begin{array}{l}{[-4.32 ;} \\
26.96]\end{array}$ & 0.44 \\
\hline & 12 a.m. to 6 a.m. & $\begin{array}{c}48.11 \\
(16.17)\end{array}$ & $\begin{array}{c}37 \\
(23.08)\end{array}$ & $\begin{array}{c}11.11 \\
(23.19)\end{array}$ & 2.09 & 0.051 & $\begin{array}{l}{[-0.07 ;} \\
22.28]\end{array}$ & 0.55 \\
\hline
\end{tabular}

\subsection{Mobility during the Night}

Mobile and immobile minutes for the control night and the night shift were compared based on the data of the Actiwatch (Table 2). For the time window of 10 p.m. to 8 a.m., the number of immobile minutes amounted to $322.6( \pm 50.1 \mathrm{~min})$ during the night shift and to 391.7 ( $\pm 53.4 \mathrm{~min}$ ) during the control night. The number of mobile minutes during the night shift exceeds those during the control night, respectively (night shift: $84 \pm 36.3 \mathrm{~min}$; control night: $63.8 \pm 38.9 \mathrm{~min}$ ). The same was true for both shorter time windows, with less immobile minutes and more mobile minutes counted during the night shift compared to the control night. The observed differences in the immobile minutes were significant for all three time windows (10 p.m. to 8 a.m.: $p<0.001 ; 11$ p.m. to 7 a.m.; $p<0.001 ; 12$ a.m. to 6 a.m.; $p<0.05$ ), while no statistically significant differences were observed for the mobile minutes (10 p.m. to 8 a.m.: $p=0.132 ; 11$ p.m. to 7 a.m.; $p=0.146 ; 12$ a.m. to 6 a.m.; $p=0.051$; Table 3). Cohen's $d$ for the differences in the immobile minutes exceeded the critical value of 0.57 for all three time windows.

\subsection{Daytime Sleepiness}

Both the ESS and the KSS revealed significantly higher scores after a night shift compared to a control night (Tables 4 and 5). Average ESS scores amounted to $11.64 \pm 3.05$ after a night on duty and to $2.09 \pm 1.87$ after a control night $(p<0.001)$. Similarly, an average KSS score of $6.77 \pm 0.81$ was determined after a night shift, while the average score after a control night was $2.41 \pm 0.59(p<0.001)$. Cohen's d exceeded the critical value for both tests (ESS: 3.81 ; KSS: 6.19).

\subsection{Concentration}

Five parameters related to concentration were analyzed with the $\mathrm{d} 2-\mathrm{R}$ tests, the mistake rate $(\mathrm{F} \%)$, the concentration ability $(\mathrm{KL})$, the mistake of mixing up objects within the test $(\mathrm{VF})$, the mistake of leaving out correct objects $(\mathrm{AF})$, and the number of marked target objects within the allowed test time (BZO) (Table 4). The three parameters identifying mistakes (F\%, 
AF, and VF) were significantly higher after a night shift compared to a control night, while significantly fewer objects were marked within the test time (BZO) and the concentration ability was significantly lower after a night shift (KL; $p<0.001$ for all d2-R parameters, Table 5). Cohen's $\mathrm{d}$ indicated a strong practical implication of all five $\mathrm{d} 2-\mathrm{R}$ parameters.

Table 4. Daytime sleepiness and concentration ability after the control night, the night shift, and in total. AF, "Auslassungsfehler"/omissions, BZO, "bearbeitete Zielobjekte"/number of completed objects; CI, confidence interval; ESS, Epworth Sleep Scale; F\%, „Fehlerquote" /mistake rate; KL, “Konzentrationsleistung”/concentration, SD, standard deviation; VF, "Verwechslungsfehler" / mix-up mistakes.

\begin{tabular}{|c|c|c|c|c|c|c|c|}
\hline \multicolumn{2}{|c|}{ Variable } & Type of Night & Mean & SD & Median & Minimum & Maximum \\
\hline \multirow{3}{*}{\multicolumn{2}{|c|}{ ESS }} & Total & 6.86 & 5.44 & 6.50 & 0 & 17 \\
\hline & & Night shift & 11.64 & 3.05 & 12 & 4 & 17 \\
\hline & & Control night & 2.09 & 1.87 & 2 & 0 & 7 \\
\hline \multirow{3}{*}{\multicolumn{2}{|c|}{ Karolinska }} & Total & 4.59 & 2.32 & 5 & 2 & 9 \\
\hline & & Night shift & 6.77 & 0.81 & 7 & 6 & 9 \\
\hline & & Control night & 2.41 & 0.59 & 2 & 2 & 4 \\
\hline \multirow{15}{*}{$\mathrm{d} 2-\mathrm{R}$} & \multirow{3}{*}{$\mathrm{BZO}$} & Total & 259.02 & 24.52 & 259.50 & 204 & 301 \\
\hline & & Night shift & 245.68 & 22.37 & 251.50 & 204 & 301 \\
\hline & & Control night & 272.36 & 18.93 & 276.50 & 208 & 299 \\
\hline & \multirow{3}{*}{$\mathrm{AF}$} & Total & 12.55 & 9.33 & 10 & 1 & 46 \\
\hline & & Night shift & 15.95 & 10.41 & 14 & 2 & 46 \\
\hline & & Control night & 9.14 & 6.76 & 6 & 1 & 28 \\
\hline & \multirow{3}{*}{ VF } & Total & 5.82 & 4.47 & 5 & 0 & 17 \\
\hline & & Night shift & 8.77 & 4.19 & 9 & 0 & 17 \\
\hline & & Control night & 2.86 & 2.27 & 2.50 & 0 & 7 \\
\hline & \multirow{3}{*}{$\mathrm{KL}$} & Total & 240.66 & 28.11 & 244 & 180 & 282 \\
\hline & & Night shift & 220.95 & 21.41 & 228 & 180 & 248 \\
\hline & & Control night & 260.36 & 18.59 & 266 & 207 & 282 \\
\hline & \multirow{3}{*}{$\mathrm{F} \%$} & Total & 7.15 & 4.73 & 6.70 & 0.10 & 21 \\
\hline & & Night shift & 9.95 & 4.79 & 8.75 & 2.40 & 21 \\
\hline & & Control night & 4.35 & 2.54 & 4.05 & 0.10 & 11 \\
\hline
\end{tabular}

Table 5. Comparison of daytime sleepiness and concentration ability between the control night and the night shift. AF, "Auslassungsfehler"/omissions, BZO, "bearbeitete Zielobjekte" / number of completed objects; CI, confidence interval; ESS, Epworth Sleep Scale; F\%, "Fehlerquote" / mistake rate; KL, "Konzentrationsleistung" / concentration, SD, standard deviation; VF, “Verwechslungsfehler”/ mix-up mistakes.

\begin{tabular}{|c|c|c|c|c|c|c|c|c|}
\hline \multirow{2}{*}{\multicolumn{2}{|c|}{ Variable }} & \multicolumn{3}{|c|}{ Mean (SD) } & \multirow{2}{*}{$\mathbf{t}$} & \multirow{2}{*}{$p$} & \multirow{2}{*}{$95 \%$ CI } & \multirow{2}{*}{ Cohen's d } \\
\hline & & Night Shift & Control Night & Difference & & & & \\
\hline \multirow{2}{*}{\multicolumn{2}{|c|}{$\begin{array}{c}\text { ESS } \\
\text { Karolinska }\end{array}$}} & $11.64(3.05)$ & $2.09(1.87)$ & $9.55(3.94)$ & 11.37 & $<0.001$ & {$[7.80 ; 11.29]$} & 3.81 \\
\hline & & $6.77(0.81)$ & $2.41(0.59)$ & $4.36(1.18)$ & 17.39 & $<0.001$ & {$[3.84 ; 4.89]$} & 6.19 \\
\hline \multirow{5}{*}{$\mathrm{d} 2-\mathrm{R}$} & $\mathrm{BZO}$ & $245.68(22.37)$ & $272.36(18.93)$ & $-26.68(15.64)$ & -8.00 & $<0.001$ & {$[-33.62 ;-19.75]$} & -1.27 \\
\hline & $\mathrm{AF}$ & $15.95(10.41)$ & $9.14(6.76)$ & $6.82(6.40)$ & 4.99 & $<0.001$ & {$[3.98 ; 9.66]$} & 0.67 \\
\hline & VF & 8.77 (4.19) & $2.86(2.27)$ & $5.91(3.78)$ & 7.34 & $<0.001$ & {$[4.23 ; 7.58]$} & 1.65 \\
\hline & KL & $220.95(21.41)$ & $260.36(18.59)$ & $-39.41(15.71)$ & -11.77 & $<0.001$ & {$[-46.37 ;-32.44]$} & -1.94 \\
\hline & $\mathrm{F} \%$ & $9.95(4.79)$ & $4.35(2.54)$ & $5.60(3.57)$ & 7.37 & $<0.001$ & {$[4.02 ; 7.19]$} & 1.25 \\
\hline
\end{tabular}

\subsection{Correlations}

A high correlation between sleep time, sleep efficiency and the number of immobile minutes was detected in the correlation analysis in both the control night and the night shift and in all three time periods assessed (Table 6). If sleep time was used to represent also sleep efficiency and immobile minutes, the correlation with daytime sleepiness and concentration was low in the control night. In contrast, higher correlations pertaining to daytime sleepiness and concentration were observed. The longer the sleep time during the night shift, the lower the VF on the concentration scale was the next day, indicating that less objectives were falsely mixed up in the d2-R-test. In turn, the shorter a participant slept, the worse his or her concentration ability was on the next day. 


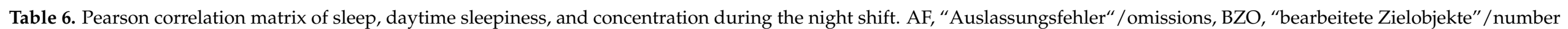

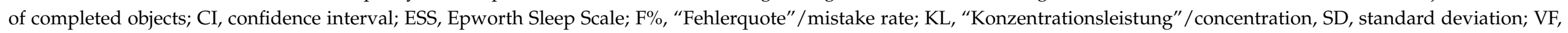

"Verwechslungsfehler" / mix-up mistakes. ${ }^{* *} p<0.01$.

\begin{tabular}{|c|c|c|c|c|c|c|c|c|c|c|c|c|c|}
\hline \multirow{2}{*}{\multicolumn{2}{|c|}{ Variable }} & \multicolumn{3}{|c|}{ Sleep Time } & \multicolumn{3}{|c|}{ Sleep Efficiency } & \multicolumn{5}{|c|}{ d2-R } & \multirow{3}{*}{ ESS } \\
\hline & & \multirow{2}{*}{$\begin{array}{c}\begin{array}{c}10 \text { p.m. to } 8 \\
\text { a.m. }\end{array} \\
0.95^{* *} \\
{[0.87 .0 .98]} \\
0.86^{* *} \\
{[0.67 .0 .95]}\end{array}$} & \multirow{2}{*}{$\begin{array}{c}11 \text { p.m. to } 7 \\
\text { a.m. } \\
\\
0.93^{* *} \\
{[0.82 .0 .97]}\end{array}$} & \multirow[t]{2}{*}{$\begin{array}{l}12 \text { a.m. to } 6 \\
\text { a.m. }\end{array}$} & \multirow[t]{2}{*}{$\begin{array}{l}10 \text { p.m. to } 8 \\
\text { a.m. }\end{array}$} & \multirow[t]{2}{*}{$\begin{array}{l}11 \text { p.m. to } 7 \\
\text { a.m. }\end{array}$} & \multirow[t]{2}{*}{$\begin{array}{l}12 \text { a.m. to } 6 \\
\text { a.m. }\end{array}$} & \multirow[t]{2}{*}{ BZO } & \multirow[t]{2}{*}{$\mathrm{AF}$} & \multirow[t]{2}{*}{ VF } & \multirow[t]{2}{*}{ KL } & \multirow[t]{2}{*}{ F\% } & \\
\hline Sleep time & $\begin{array}{l}11 \text { p.m. to } 7 \\
\text { a.m. } \\
0 \text { a.m. to } 6 \\
\text { a.m. }\end{array}$ & & & & & & & & & & & & \\
\hline $\begin{array}{c}\text { Sleep } \\
\text { efficiency }\end{array}$ & $\begin{array}{l}10 \text { p.m. to } 8 \\
\text { a.m. } \\
11 \text { p.m. to } 7 \\
\text { a.m. } \\
0 \text { a.m. to } 6 \\
\text { a.m. }\end{array}$ & $\begin{array}{c}1.00^{* *} \\
{[1.00 .1 .00]} \\
0.95^{* *} \\
{[0.88 .0 .98]} \\
0.86^{* *} \\
{[0.67 .0 .95]}\end{array}$ & $\begin{array}{c}0.95^{* *} \\
{[0.87 .0 .98]} \\
1.00^{* *} \\
{[1.00 .1 .00]} \\
0.93^{* *} \\
{[0.82 .0 .97]}\end{array}$ & $\begin{array}{c}0.86^{* *} \\
{[0.67 .0 .95]} \\
0.93 * * \\
{[0.82 .0 .97]} \\
1.00^{* *} \\
{[1.00 .1 .00]}\end{array}$ & $\begin{array}{c}0.95^{* *} \\
{[0.88 .0 .98]} \\
0.86^{* *} \\
{[0.67 .0 .95]}\end{array}$ & $\begin{array}{c}0.93 * * \\
{[0.83 .0 .97]}\end{array}$ & & & & & & & \\
\hline $\mathrm{d} 2-\mathrm{R}$ & $\begin{array}{l}\text { VF } \\
\text { KL }\end{array}$ & $\begin{array}{c}-0.34 \\
{[-0.69} \\
0.14] \\
0.13 \\
{[-0.34 .} \\
0.55] \\
-0.59 * * \\
{[-0.82} \\
-0.18] \\
-0.30 \\
{[-0.66 .} \\
0.18] \\
-0.01 \\
{[-0.46} \\
0.45]\end{array}$ & $\begin{array}{c}-0.24 \\
{[-0.63 .} \\
0.24] \\
0.20 \\
{[-0.28 .} \\
0.60] \\
-0.40 \\
{[-0.73 .} \\
0.06] \\
-0.27 \\
{[-0.64 .} \\
0.21] \\
0.10 \\
{[-0.37 .} \\
0.53] \\
\end{array}$ & $\begin{array}{c}-0.12 \\
{[-0.55 .} \\
0.35] \\
0.17 \\
{[-0.31 .} \\
0.58] \\
-0.32 \\
{[-0.67 .} \\
0.16] \\
-0.15 \\
{[-0.57 .} \\
0.33] \\
0.08 \\
{[-0.38 .} \\
0.52]\end{array}$ & $\begin{array}{c}-0.33 \\
{[-0.68 .} \\
0.14] \\
0.13 \\
{[-0.34 .} \\
0.55] \\
-0.59 * * \\
{[-0.82 .} \\
-0.18] \\
-0.30 \\
{[-0.66 .} \\
0.18] \\
-0.01 \\
{[-0.46 .} \\
0.45]\end{array}$ & $\begin{array}{c}-0.24 \\
{[-0.63 .} \\
0.24] \\
0.20 \\
{[-0.28 .} \\
0.60] \\
-0.41 \\
{[-0.73 .} \\
0.06] \\
-0.27 \\
{[-0.64 .} \\
0.21] \\
0.10 \\
{[-0.38 .} \\
0.53] \\
\end{array}$ & $\begin{array}{c}-0.12 \\
{[-0.55 .} \\
0.35] \\
0.17 \\
{[-0.31 .} \\
0.58] \\
-0.32 \\
{[-0.68 .} \\
0.16] \\
-0.15 \\
{[-0.57 .} \\
0.32] \\
0.08 \\
{[-0.38 .} \\
0.52]\end{array}$ & $\begin{array}{c}0.20 \\
{[-0.28 .} \\
0.60] \\
0.36 \\
{[-0.11 .} \\
0.70] \\
0.86 * * \\
{[0.66 .0 .94]} \\
0.05 \\
{[-0.42 .} \\
0.49]\end{array}$ & $\begin{array}{c}0.17 \\
{[-0.31 .} \\
0.58] \\
-0.31 \\
{[-0.67 .} \\
0.17] \\
0.92 * * \\
{[0.80 .0 .97]}\end{array}$ & $\begin{array}{c}0.11 \\
{[-0.36 .} \\
0.54] \\
0.44 \\
{[-0.02 .} \\
0.75]\end{array}$ & $\begin{array}{l}-0.47^{*} \\
{[-0.76} \\
-0.02]\end{array}$ & & \\
\hline & & $\begin{array}{c}-0.22 \\
{[-0.61 .} \\
0.26]\end{array}$ & $\begin{array}{c}-0.15 \\
{[-0.57} \\
0.33]\end{array}$ & $\begin{array}{c}-0.06 \\
{[-0.50 .} \\
0.41]\end{array}$ & $\begin{array}{c}-0.22 \\
{[-0.61} \\
0.26]\end{array}$ & $\begin{array}{c}-0.15 \\
{[-0.57} \\
0.33]\end{array}$ & $\begin{array}{c}-0.05 \\
{[-0.49 .} \\
0.41]\end{array}$ & $\begin{array}{c}-0.05 \\
{[-0.50 .} \\
0.41]\end{array}$ & $\begin{array}{c}0.41 \\
{[-0.05 .} \\
0.73]\end{array}$ & $\begin{array}{c}0.44 \\
{[-0.02 .} \\
0.74]\end{array}$ & $\begin{array}{c}-0.33 \\
{[-0.68} \\
0.15]\end{array}$ & $\begin{array}{c}0.59^{* *} \\
{[0.18 .0 .82]}\end{array}$ & \\
\hline Kar & nska & $\begin{array}{c}-0.40 \\
{[-0.72 .} \\
0.06]\end{array}$ & $\begin{array}{c}-0.25 \\
{[-0.63} \\
0.23]\end{array}$ & $\begin{array}{c}-0.26 \\
{[-0.64} \\
0.22]\end{array}$ & $\begin{array}{c}-0.40 \\
{[-0.72 .} \\
0.06]\end{array}$ & $\begin{array}{c}-0.25 \\
{[-0.63} \\
0.23]\end{array}$ & $\begin{array}{c}-0.26 \\
{[-0.64 .} \\
0.22]\end{array}$ & $\begin{array}{c}0.15 \\
{[-0.32 .} \\
0.57]\end{array}$ & $\begin{array}{c}0.45 \\
{[-0.00 .} \\
0.75]\end{array}$ & $\begin{array}{c}0.61 * * \\
{[0.21 .0 .83]}\end{array}$ & $\begin{array}{c}-0.17 \\
{[-0.58} \\
0.31]\end{array}$ & $\begin{array}{c}0.58 * * \\
{[0.17 .0 .82]}\end{array}$ & $\begin{array}{c}0.58^{* *} \\
{[0.16 .0 .82]}\end{array}$ \\
\hline
\end{tabular}




\section{Discussion}

For the first time, we identified an impact of night shift work of pharmacists on their sleep duration and sleep efficiency. Compared to a control night, pharmacists were mobile for longer periods and demonstrated an increased daytime sleepiness on the following day. Furthermore, pharmacists showed a diminished concentration ability after a night shift that correlated with daytime sleepiness.

The continuous closure of pharmacies renders pharmacy managers in Germany responsible for numerous tasks and increases the number of nights they are on duty. At the same time, they frequently continue work after a night shift, which may impair their concentration and hence the safe distribution of medicines. In the present study, the impact of night duties on daytime sleepiness and concentration ability was assessed.

The results show that pharmacists on night duty slept considerably less and with a reduced efficiency during nights on duty compared to control nights. This significantly impaired their concentration ability during the day and increased their daytime sleepiness. Significant differences between the control night and the night on duty were observed for all three time frames and for three of the four parameters evaluated (sleep time, sleep efficiency, immobile minutes), while the number of mobile minutes did not differ between both nights. Particularly, the fact that the concentration was significantly impaired after a night shift is of concern, considering the responsibility the pharmacists have regarding blistering, fulfillment of prescriptions, and laboratory analyses. The impairment of concentration after a night shift has been documented for several other health care professions and concerns for the wellbeing of these professional groups and the safety of the patients have been raised [11,12,16-18].

German legislation requires pharmacies to be on call at all times to ensure the constant supply of medicines. This applies on working days, weekends and public holidays and is intended to secure the supply, especially when other sectors of the economy are at rest. The pharmacy on-call service is not regarded as a way for pharmacies to operate economically outside of store opening hours, but rather as an emergency service that guarantees the population rapid access to medicines. This on-call service is normally permanent, although it is up to the competent authority to exempt a certain proportion of pharmacies from this on-call duty during certain periods. If there is no exemption, the pharmacy manager or a person authorized to represent him must be always available during the on-call hours. The pharmacy manager can be represented by a pharmacist, but this is only possible if this person is a permanent substitute and a substitution is, therefore, the exception.

Based on the results of the present study, the need to address this issue in pharmacy policy and legislation is obviated. The goal of the health authority is to ensure a uniform exemption for pharmacies. However, this does not always prove possible in practice. Strategies to determine and alleviate the on-duty hours of pharmacy managers appear essential in improving their wellbeing while ensuring the safety of the customers. Importantly, the suitability of an actimeter to assess the sleep duration, efficiency, and mobility during a night on duty was demonstrated herein and hence it could offer a valuable tool in analyzing these factors for healthcare workers on night shifts. Moreover, policies to attract young pharmacists to rural areas and support their self-employment as community pharmacists are indicated.

The present study has certain limitations that should be addressed. First, it must be considered a pilot study due to the low number of participants. Therefore, no inclusion and exclusion criteria were defined but should define the cohort of future studies. Second, only one region of Germany was assessed, which should be extended to a more representative sample with pharmacists from several geographical regions. Third, data was collected for each participant during and after a control night and a night shift. Last, the ESS and KSS questionnaires are subjective measures of daytime sleepiness and hence the results obtained using these questionnaires may not be generally extrapolated. Nonetheless, the $\mathrm{d} 2 \mathrm{R}$ questionnaire offers an objective measure, and hence the results are considered less subjective and more reliably transposable. Although the $\mathrm{d} 2-\mathrm{R}$ has not been specifically 
validated for pharmacists, it is a standard tool to assess concentration ability. The items assessed, particularly counting and distinguishing objects under time pressure, are relevant for the pharmacists, i.e., in counting pills and distinguishing pills with a similar appearance. In addition, the ESS scores of $>10$ are comparable with previous studies on sleepiness after a night shift in nurses [19], medical residents [20,21], and emergency physicians [22]. Last, the circadian tendency of participants was not taken into account due to the small sample size. It is feasible to assume that participants with eveningness tendencies may perform better on night shifts compared to those with a morning tendency. The results of the present pilot study indicate that future studies on larger cohorts are worth assessing the impact of night duty on daytime sleepiness and identify policies to improve workplace safety of pharmacists and other healthcare workers.

\section{Conclusions}

The present pilot study gives an indication of the negative impact of extensive night shift work on daytime sleepiness and performance and as a consequence safety of medication distribution. Due to the limitations of the study, future studies should investigate the impact of night shifts in a larger cohort of pharmacists and ideally during several consecutive night shifts to exclude any confounders such as incidental events during one night shift and personal situations of the few pharmacists investigated herein.

Author Contributions: Conceptualization, T.P. and C.W.B.; data curation, C.W.B.; formal analysis, C.W.B. and T.P.; funding acquisition, T.P.; investigation, C.W.B.; methodology, C.W.B.; project administration, T.P.; resources, C.W.B. and T.P.; software, C.W.B.; supervision, T.P.; validation, C.W.B., M.G., I.F., J.K. and T.P.; visualization, C.W.B.; writing-original draft, C.W.B. and T.P.; writing-review and editing, C.W.B., M.G., I.F., J.K. and T.P. All authors have read and agreed to the published version of the manuscript.

Funding: This work was partially supported by the Project of Russian Federation Government, Grant No. 075-15-2019-1885. The authors report no other funding related to this study.

Institutional Review Board Statement: Ethical approval was obtained by the Ethics Board of the Charité Universitätsmedizin (approval number: EA1/240/19).

Informed Consent Statement: All participants were informed of their voluntary participation in the study and gave their informed consent.

Data Availability Statement: The data presented in this study are available on request from the corresponding author.

Acknowledgments: We thank C. Pilz for organizing the actimeter recordings and the LAK for contributing policy and organizational documents. We further thank S. Zimmermann for support with the ethics applications.

Conflicts of Interest: The authors declare no conflict of interest.

\section{References}

1. German Medical Association (BÄK) and Association for Statutory Health Insurance Physicians (KBV). Zahl der Apotheken in Rheinland-Pfalz nimmt immer weiter ab. Deutsches Ärzteblatt. 2021. Available online: https:/ /www.aerzteblatt.de/nachrichten/ sw / Apotheken? $=\& p=1 \& n=1 \& n i d=120508$ (accessed on 31 August 2021).

2. van de Pol, J.; Koster, E.; Hövels, A.; Bouvy, M. Balancing traditional activities and cognitive pharmaceutical services by community pharmacists: A work sampling study. Int. J. Clin. Pharm. 2019, 41, 872-879. [CrossRef] [PubMed]

3. Johnson, S.J.; O'Connor, E.M.; Jacobs, S.; Hassell, K.; Ashcroft, D.M. The relationships among work stress, strain and self-reported errors in UK community pharmacy. Res. Social Adm. Pharm. 2014, 10, 885-895. [CrossRef] [PubMed]

4. Aarrebo Jensen, M.; Hansen, Å.M.; Sallerup, M.; Odgaard Nielsen, N.; Schlünssen, V.; Helene Garde, A. Acute effects of night work and meals on blood glucose levels. Chronobiol. Int. 2020, 1-8. [CrossRef] [PubMed]

5. Chellappa, S.L.; Morris, C.J.; Scheer, F. Circadian misalignment increases mood vulnerability in simulated shift work. Sci. Rep. 2020, 10, 18614. [CrossRef] [PubMed]

6. Thun, E.; Waage, S.; Bjorvatn, B.; Moen, B.E.; Vedaa, Ø.; Blytt, K.M.; Pallesen, S. Short sleep duration and high exposure to quick returns are associated with impaired everyday memory in shift workers. Nurs. Outlook 2020. [CrossRef] [PubMed] 
7. Grant, C.L.; Dorrian, J.; Coates, A.M.; Pajcin, M.; Kennaway, D.J.; Wittert, G.A.; Heilbronn, L.K.; Vedova, C.D.; Gupta, C.C.; Banks, $\mathrm{S}$. The impact of meal timing on performance, sleepiness, gastric upset, and hunger during simulated night shift. Ind. Health 2017, 55, 423-436. [CrossRef] [PubMed]

8. Al-Naimi, S.; Hampton, S.M.; Richard, P.; Tzung, C.; Morgan, L.M. Postprandial metabolic profiles following meals and snacks eaten during simulated night and day shift work. Chronobiol. Int. 2004, 21, 937-947. [CrossRef] [PubMed]

9. Van Dongen, H.P. Shift work and inter-individual differences in sleep and sleepiness. Chronobiol. Int. 2006, 23, 1139-1147. [CrossRef] [PubMed]

10. Ruggiero, J.S.; Redeker, N.S. Effects of napping on sleepiness and sleep-related performance deficits in night-shift workers: A systematic review. Biol. Res. Nurs. 2014, 16, 134-142. [CrossRef] [PubMed]

11. James, L.; James, S.M.; Wilson, M.; Brown, N.; Dotson, E.J.; Dan Edwards, C.; Butterfield, P. Sleep health and predicted cognitive effectiveness of nurses working 12-h shifts: An observational study. Int. J. Nurs. Stud. 2020, 103667. [CrossRef] [PubMed]

12. Costa, C.; Mondello, S.; Micali, E.; Indelicato, G.; Licciardello, A.A.; Vitale, E.; Briguglio, G.; Teodoro, M.; Fenga, C. Night shift work in resident physicians: Does it affect mood states and cognitive levels? J. Affect. Disord. 2020, 272, 289-294. [CrossRef] [PubMed]

13. Sanches, I.; Teixeira, F.; dos Santos, J.M.; Ferreira, A.J. Effects of Acute Sleep Deprivation Resulting from Night Shift Work on Young Doctors. Acta. Med. Port. 2015, 28, 457-462. [CrossRef] [PubMed]

14. Buysse, D.J.; Reynolds, C.F., 3rd; Monk, T.H.; Berman, S.R.; Kupfer, D.J. The Pittsburgh Sleep Quality Index: A new instrument for psychiatric practice and research. Psychiatry Res. 1989, 28, 193-213. [CrossRef]

15. Cohen, J. Statistical Power Analysis for the Behavioral Sciences, 2nd ed.; Academic Press: New York, NY, USA, 1988.

16. Larsen, A.D.; Ropponen, A.; Hansen, J.; Hansen, Å.M.; Kolstad, H.A.; Koskinen, A.; Härmä, M.I.; Garde, A.H. Working time characteristics and long-term sickness absence among Danish and Finnish nurses: A register-based study. Int. J. Nurs. Stud. 2020, 112, 103639. [CrossRef] [PubMed]

17. Boettcher, C.; Sommer, G.; Peitzsch, M.; Zimmer, K.P.; Eisenhofer, G.; Wudy, S.A. Differential Responses of Urinary Epinephrine and Norepinephrine to 24-h Shift-Work Stressor in Physicians. Front. Endocrinol. 2020, 11, 572461. [CrossRef] [PubMed]

18. Landrigan, C.P.; Rahman, S.A.; Sullivan, J.P.; Vittinghoff, E.; Barger, L.K.; Sanderson, A.L.; Wright, K.P., Jr.; O’Brien, C.S.; Qadri, S.; St Hilaire, M.A.; et al. Effect on Patient Safety of a Resident Physician Schedule without 24-Hour Shifts. N. Engl. J. Med. 2020, 382, 2514-2523. [CrossRef] [PubMed]

19. Surani, S.R.; Subramanian, S.; Aguillar, R.; Gnananandh, J.; Parrish, B. SLEEP QUANTITY AND SLEEPINESS IN DAY- AND NIGHT-SHIFT NURSES. CHEST 2007, 132, 503A. [CrossRef]

20. Alami, Y.Z.; Ghanim, B.T.; Zyoud, S.e.H. Epworth sleepiness scale in medical residents: Quality of sleep and its relationship to quality of life. J. Occup. Med. Toxicol. 2018, 13, 21. [CrossRef] [PubMed]

21. Purim, K.; Guimarães, A.; Titski, A.; Leite, N. Sleep deprivation and drowsiness of medical residents and medical students. Rev. Col. Bras. Cir. 2016, 43, 438-444. [CrossRef] [PubMed]

22. Alhifzi, S.; Al-Ghonimy, A.; Al Aboudi, M.; Al Abdullah, R.; Olaish, A.; BaHammam, A. Assessment of Sleep Quality, Daytime Sleepiness, and Depression among Emergency Physicians Working in Shifts. J. Nat. Sci. Med. 2018, 1, 17-21. [CrossRef] 